\title{
COMPLICATIONS OF TRACHEOBRONCHIAL FOREIGN BODY ASPIRATION IN CHILDREN: REPORT OF 5 CASES AND REVIEW OF THE LITERATURE
}

\author{
Cláudio Flauzino de Oliveira, João Fernando Lourenço de Almeida, Eduardo \\ Juan Troster and Flavio Adolfo Costa Vaz
}

\begin{abstract}
OLIVEIRA CF de et al. - Complications of tracheobronchial foreign body aspiration in children : report of 5 cases and review of the literature. Rev. Hosp. Clín. Fac. Med. S. Paulo 57(3): 2002.

Foreign body aspiration (FBA) is one of leading causes of death in children, especially among those younger than 3 years of age. The inhalation of a foreign body may cause a wide variety of symptoms, and early diagnosis is highly associated with the successful removal of the inhaled foreign material. Despite the great advances in endoscopic procedures and anesthesia, a large number of difficulties and complications still result from foreign body aspiration. We describe 5 cases of serious acute complications following aspiration of foreign bodies that became lodged in the tracheobronchial tree, including pneumomediastinum, pneumothorax, total atelectasis, foreign body dislodgment, and need for thoracotomy in children admitted into our intensive care unit in 1999 and 2000; these were all situations that could have been prevented with early recognition and prompt therapeutic intervention.
\end{abstract}

\section{DESCRIPTORS: Key words. Aspiration. Foreign body. Bronchoscopy. Complications.}

Foreign body aspiration (FBA) is a very common occurrence in children, especially among those younger than 3 years of age $(79 \%)^{1}$, with a higher incidence in boys $(63 \%)^{2}$. Sometimes, FBA can be life threatening, acting as a significant cause of fatal home accidents in children younger than 6 years ${ }^{3}$ and causing more than 300 deaths per year in the United States ${ }^{4}$. This higher occurrence in children has also been confirmed in a retrospective Brazilian study $^{5}$.

Usually, there is a suggestive history of choking, although the classic clinical presentation, with coughing, wheezing, and diminished air inflow, is seen in less than $40 \%$ of the patients ${ }^{1,6,7}$; other symptoms include cyanoses, fever, and stridor. Sometimes, FBA can be completely assymptomatic ${ }^{2}$. The evolution of FBA can lead to variable degrees of respiratory distress, atelectasis, chronic coughing, recurrent pneumonia, and even death ${ }^{1,6,7}$.

Most frequently, aspirated objects are food, which is involved in $75 \%$ of the cases; other organic materials, such as bones, teeth, and plants, $7 \%$; nonorganic materials, such as metals and plastics, $13 \%$; rocks, $1 \%$; and toys or parts of toys, $1 \%{ }^{8}$. Aspiration of foreign bodies that become lodged in the tracheobronchial tree comprise a small subset of FBA cases. The location of lodging of the foreign bodies has been shown to be $48 \%$ to $49 \%$, in the right lung; $39 \%$ to $44 \%$, in the left lung; and

From the Pediatric Intensive Care Unit of the Childrens Institute, Hospital das Clínicas, Faculty of Medicine, University of São Paulo. only $4 \%$ to $13 \%$ between the larynx and trachea ${ }^{1,8}$. In isolated cases, foreign bodies have been shown to migrate and change location ${ }^{7}$.

Diagnosis of FBA begins with patient history, and clinical exploration and can be strengthened by radiographic findings. The most common indicators are air trapping, signs of infection, atelectasis, or radioopaque foreign bodies ${ }^{9}$. However, these findings can also occur in a patient without FBA. In addition, 24\% of the patients with an endoscopically confirmed foreign body do not present with any abnormality at radiography. Thus, although it may help, thorax radiography is not sufficiently sensitive or specific for the diagnosis of $\mathrm{FBA}^{7,9}$. Hence, its important to note that children with these characteristic symptoms should undergo prompt bronchoscopy, regard- 
of radiographic findings ${ }^{1,10}$.

Nowadays, bronchoscopy is essential if FBA is suspected, first to confirm the diagnosis and also because it can be used for therapeutic treatment in the same stage. Before the advent of bronchoscopic techniques, the mortality rate for FBA was around $50 \%$ of the cases ${ }^{11}$. Now, with bronchoscopy available and advances in anesthesiology and surgical procedures, both mortality and morbidity have markedly diminished ${ }^{1,12,13}$.

The complications of FBA can be divided in two groups: complications related to the foreign body itself and complications following the bronchoscopic procedure.

Foreign body aspiration and its evolution can lead to complications such as pneumomediastinum, pneumothorax, hydropneumothorax, bronchial stenosis, abscess, atelectasis, pneumonia, bronchiectasis, foreign body dislodgment, and bronchoespasm. ${ }^{6,714-18}$ The presence of these complications in children is about $22 \%$ to $33 \%$, and the most common is pneumonia $^{19,20}$.

Furthermore, the patient can develop complications resulting from the bronchoscopy. Usually, the foreign body is successfully removed with bronchoscopy in a simple and safe way ${ }^{9}$. However, complications may occur in $6 \%$ to $8 \%$ of the procedures and can be significant ones, such as pneumomediastinum, trachea laceration, vocal cords laceration, sub-glottic edema, and necessity for thoracotomy, bronchotomy, or lobectomy $5,8,10$.

\section{REPORTS}

Case 1 - A 9-month-old girl, previously healthy, presented with a history of 1 day with fever, productive coughing and short breath. She had already been diagnosed as having pneumonia and was already taking antibiotics, but had returned to the hospital because of worsening of the respiratory distress. Presenting with respiratory failure, she was intubated at admission, and her thorax radiography revealed atelecta-

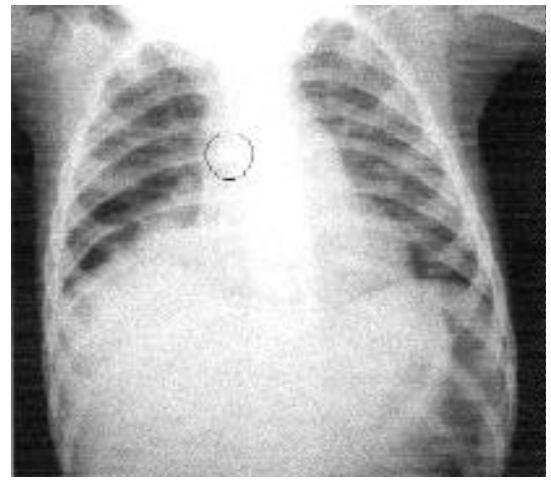

Case $1 \mathrm{~A}$ - First X-ray which was interpreted as pneumonia; circle shows the foreign body in the right main bronchus.

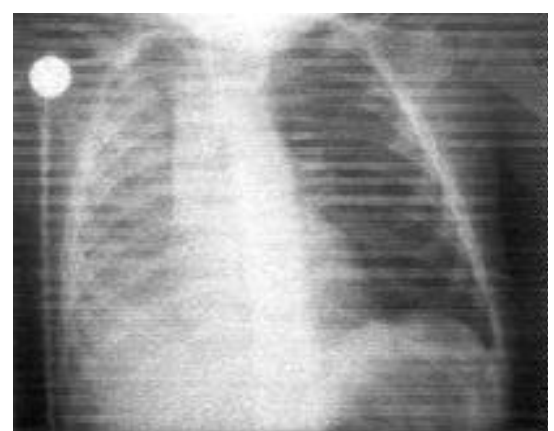

Case 1 B - Lateral view; circle shows the foreign body.

sis of right lung and the presence of foreign body in the right side. On the following day, bronchoscopy did not show the foreign body in the right side, but found a rock in the left bronchus, indicating that it had migrated from right, as seen at the radiography, to the left. The foreign body was successfully extracted.

Case 2 - A 5-year-old boy, previously healthy, presented with fever, productive coughing and short breath that had commenced 5 days before; he reported "he had swallowed a toy's lamp". Thorax radiography revealed the foreign body. During bronchoscopy, the foreign body was found at the right main bronchus, but the first attempt to remove the lamp was unsuccessful-it broke into pieces and just part of it was extracted. The boy presented with pneumomediastinum and was transferred to the intensive care unit, where he improved after a period under mechanical ventilation and treatment with antibiotics and corticosteroids. He was sent home and returned after 2 weeks for

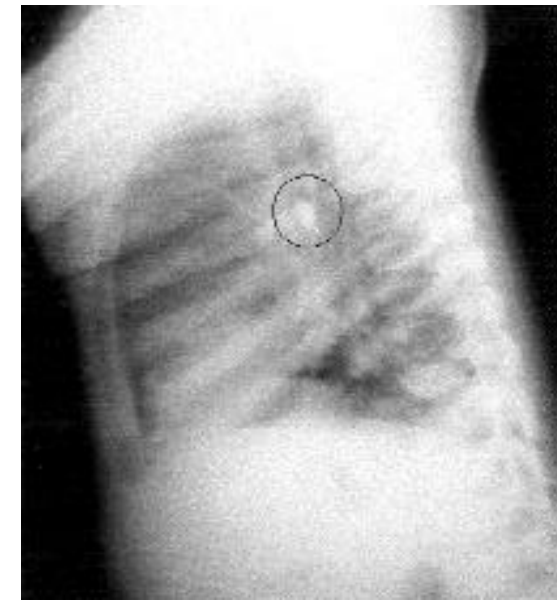

Case $1 \mathrm{C}$ - Atelectasis of right lung and pneumomediastinum, after extraction of the foreign body from the left main bronchus.

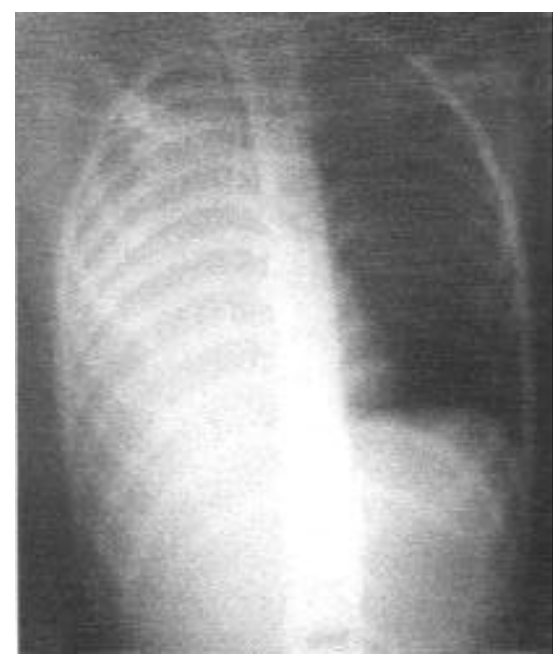

Case 3 - Total atelectasis of right lung; olive seed was extracted from right main bronchus.

another bronchoscopy that showed a foreign body in the right inferior lobe, which could not be removed; 15 days later, he underwent a thoracotomy, and the foreign body was extracted.

Case 3 - A 5-year-old boy, previously healthy, presented with a history of foreign body aspiration 1 day before admission. The child had no symptoms in the first 3 hours at home, but suddenly developed severe respiratory distress. In the emergency room, he arrived in cardiopulmonary arrest and was promptly intubated and reanimated. Thorax radiography showed total atelectasis in the right side. Bronchoscopy was performed, and an olive seed was removed from right main bronchus. 


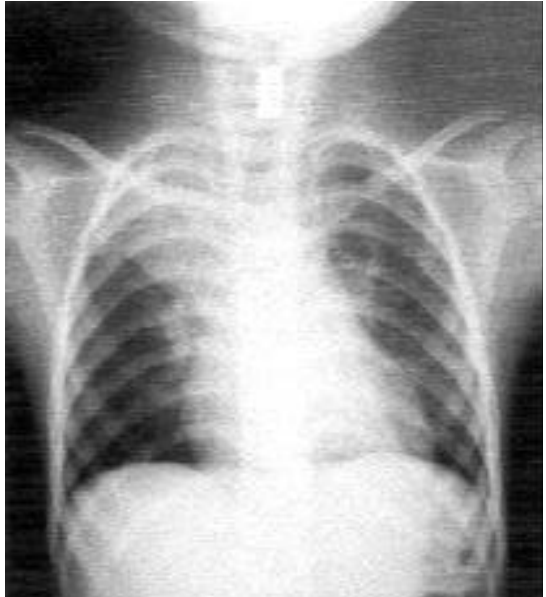

Case 5 - Atelectasis of right apex; note the coil and the endotracheal tube just above it, explaining the difficulties in placing the tube.

Case 4 - A 2-year-old boy, with a history of foreign body aspiration 72 hours before admission, presented with tachydyspnea and stridor. Bronchoscopy revealed a peanut, but despite several attempts, it was not possible to remove it, and the peanut migrated to the left main bronchus. The patient developed total atelectasis in the left lung, pneumomediastinum, pneumothorax, pneumoperitoneum, and subcutaneous emphysema. The peanut was successfully removed during a second bronchoscopy, but after a worsening in his respiratory status, a third bronchoscopy showed complete rupture of left main bronchus wall. The patient underwent a thoracotomy to repair the rupture.

Case 5 - A 3-year-old boy, previously healthy, with a history of 8 days of hoarseness and 4 days of stridor and short breath, presented with respiratory failure at admission. He was receiving inalatory Beta 2 adrenergic agonist. Intubation was unsuccessfully tried with a number $4.5 \mathrm{~mm}$ endotracheal tube, followed by attempts with $4.0 \mathrm{~mm}, 3.5$ $\mathrm{mm}$, and $3.0 \mathrm{~mm}$ tubes; intubation was finally achieved, but ventilation was still poor. Thorax radiography revealed the presence of a metal coil just below the endotracheal tube. Bronchoscopy was performed and the coil was removed; a significant granulomatous formation around the foreign body was noted.

\section{DISCUSSION}

Foreign body aspiration is a very frequently occurring situation in pediatric practice; however, it is not always immediately diagnosed, partly because this diagnosis is not frequently in mind, but also because FBA does not have a specific clinical manifestation. FBA can be result in a great variety of symptoms of varying severity, or it even can be completely asymptomatic. These differences stem in part from a variety of diverse cultural, social and economic factors that include the parents' attitudes, eating habits, the availability and types of potentially threatening objects, and prevention strategies.

The severity of the complications of FBA is frequently underestimated. Although some studies report a low percentage of serious complications, they are in fact more common than it is normally reported and are more severe in those patients who have the foreign body located in the tracheobronchial tree for a prolonged time ${ }^{5,12,18}$.

Even bronchoscopy, considered a safe technique, carries a risk of complications that has received little emphasis in other reviews. In fact, these potential complications are significant and may occur even in experienced hands, primarily when the foreign body is located in distal areas ${ }^{10}$.

Furthermore, although most cases have a benign evolution, complications may be severe and life threatening, as we saw in the cases reported above.

Some peculiar aspects must be emphasized concerning the cases described. The first and most important was the fact that in all the 5 cases, diagnosis was delayed from 1 to 8 days. In some of the cases, the family was responsible for the late diagnosis, which reinforces the critical importance of prevention strategies and information campaigns. For example, in case 2 , the child reported that he had swallowed a lamp, but his parents only took him to the hospital after 5 days when he became symptomatic. In other cases, like the first and fifth ones, the patients had been evaluated by pediatricians and were receiving either antibiotics or beta 2 adrenergic agonist agents before the correct diagnosis, leading to an increase in morbidity.

Concerning the type of objects aspirated, 3 of the cases involved rarely aspirated foreign bodies-a toy's lamp, a rock, and a coil, which historically have comprised only $1 \%$ of the cases of FBA. The fact that these foreign bodies were not common ones for FBA cases did not correlate with a better evolution, since these 3 patients required intubation and ventilatory support.

The importance of the involvement of a skilled pediatric surgeon was highlighted by case 4 . The first bronchoscopy was performed by a surgeon who was not accustomed to treating children. In addition to not accomplishing the complete removal of the foreign body, the bronchoscopy was characterized by intense manipulation that led to a severe complication-total rupture of the bronchus and the necessity for a thoracotomy.

\section{CONCLUSION}

Foreign body aspiration by children is a serious and life-threatening situation that requires special attention of parents and health-care providers. The symptoms are nonspecific, and the chest radiograph findings are frequently normal or display abnormalities uncharacteristic for FBA. Hence, children with suspicious history or symptoms should undergo prompt bronchoscopy regardless of the radiologic findings. To reduce morbidity and avoid more serious complications, attention must be given to early recognition of FBA, as well as to prompt identification of complications caused by the bronchoscopy. 
OLIVEIRA CF de e col. - Complicações de aspiração de corpo estranho traqueobrônquico em crianças: relato de 5 casos e revisão da literatura. Rev. Hosp. Clín. Fac. Med. S. Paulo 57(3): 2002.

Aspiração de corpo estranho em via áerea é uma das principais causas de morte em crianças, especialmente nas menores que 3 anos de idade. A aspiração do corpo estranho pode causar um amplo espectro de sintomas, e o diagnóstico precoce é altamente associado com o sucesso da retirada do material inalado. Apesar dos grandes avanços nos procedimentos endoscópicos e anestésicos, um grande número de dificuldades e complicações ainda estão presentes nesta situação clínica. Neste estudo, descrevemos 5 casos de sérias complicações agudas, incluindo pneumomediatismo, pneumotórax, atelectasia total, migração do corpo estranho e necessidade de toracotomia, em crianças admitidas em nosso Centro de Terapia Intensiva em 1999 e 2000, situações essas que poderiam ser prevenidas com reconhecimento precoce e rápida intervenção terapêutica.

DESCRIPTORS: Unitermos. Aspiração. Corpo estranho. Broncoscopia. Complicações.

\section{References}

1. BLACK RE, JOHNSON DG \& MATLAK ME - Bronchoscopic removal of aspirated foreign bodies in children. J Pediatr Surg 1994;29:682-4.

2. LAKS Y \& BARZILAY Z - Foreign body aspiration in childhood. Pediatr Emerg Care 1988;4:102-6.

3. GEENSHER J - Aspiration accidents. In: MCINTIRE MS, ed. Handbook on accident prevention. Maryland, Harper and Row, 1980. p.:49-52.

4. ACCIDENT facts. Chicago, National Safety Council, 1991. p. 24.

5. CATANEO AJ, REIBSCHEID SM, RUIZ JUNIOR RL et al. - Foreign body in the tracheobronchial tree. Clin Pediatr (Phila) 1997;36:701-6.

6. WISEMAN NE - The diagnosis of foreign body aspiration in childhood. J Pediatr Surg 1984;19:531-535.

7. TRAVASSOS Jr. RR, BARBAS SV, FERNANDES JM et al. - Foreign-body aspiration in adults. Rev Hosp Clin Fac Med S Paulo 1991;46:193-5.

8. CAUSEY AL, TALTON DS, MILLER RC et al. - Aspirated safety pin requiring thoracotomy: report of a case and review. Pediatr Emerg Care 1997;13:397-400.

9. SVEDSTROM E, PHAKKA H \& KERO P - How accurate is chest radiography in the diagnosis of tracheobronchial foreign bodies in children? Pediatr Radiol 1989;19:520-2.

10.ZERELLA JT, DIMLER M, MCGILL LC et al. - Foreign body aspiration in children: value of radiography and complications of bronchoscopy. J Pediatr Surg 1998;33:1651-4.

11.JACKSON C - Observations on the pathology of foreign bodies in the air and food passages: based on the analysis of 628 cases. Surg Gynecol Obstet 1919;28:201-61.
12. BLACK RE, CHOI KJ, SYME WC et al. - Bronchoscopic removal of aspirated foreign bodies in children. Am J Surg 1984;31:937941.

13. DEBELJAK A, SORLI J, MUSIC E et al. - Bronchoscopic removal of foreign bodies in adults: experience with 62 patients from 1974-1998. Eur Respir J 1999;14:792-5.

14. OZDEMIR A, COSENTINO CM, SIWIK AS et al. - Radiological case of the month. Orange seed aspiration. Arch Pediatr Adoles Med 1998;152:921-2.

15. MEGHJEE SP \& THOMAS E - Images in medicine. Foreign body aspiration. Postgrad Med J 1998;74:703.

16. BURTON EM, RIGGS W JR, KAUFMAN RA et al. - Pneumomediastinum caused by foreign body aspiration in children. Pediatr Radiol 1989;20:45-7.

17. LUH SP \& LEE YC - Foreign body aspiration with mediastinal migration and superior vena cava penetration. Chest 1994;105:1923-4.

18. METRANGOLO S, MONETTI C, MENEGHINI L et al. - Eight years' experience with foreign body aspiration in children: what is really important for a timely diagnosis? J Pediatr Surg 1999;34:1229-31.

19. BLAZER S, NAVEH Y \& FRIEDMAN A - Foreign body in the airway - a review of 200 cases. Am J Dis Child 1980; 134:6871.

20. STEEN KH \& ZIMMERMANN T - Tracheobronchial aspiration of foreign bodies in children: a study of 94 cases. Laryngoscope 1990;100:525-30.

Received for publication on July 30, 2001 